\title{
A Game System for Learning Mathematics with Pacing Considering Individual Motivation and Feeling
}

\author{
Nobumitsu SHIKINE ${ }^{1}$, Toshimasa YAMANAKA ${ }^{2}$, Junichi HOSHINO ${ }^{3}$ \\ University of Tsukuba, $\left\{{ }^{1}\right.$ Graduate School of Integrative and Global Majors, ${ }^{2}$ Faculty of \\ Art and Design, ${ }^{3}$ Faculty of Engineering, Information and Systems $\}$, Tsukuba, Japan \\ \{shikine-shikine@entcomp.esys, tyam@geijutsu,jhoshino@esys\}.tsukuba.ac.jp
}

\begin{abstract}
In these days, there are many e-learning system for studying by yourself. In these systems, learner can make their own pacing in for each learning section. But many learner needs more shorter term pacing adjusted to individual motivation and feeling in one session. Many video learning system has lack of interaction. On the other hand, novel game type e-learning system can interact to learner. But, previous novel game system can not keep the prosody information. So this paper proposed new novel game system "NOVELICA" which segmented the lesson to conversation size. And you can easily see the head of conversation with no stress by using NOVELICA. We compared with NOVELICA to previous novel game system and video learning system. And we investigate how different in these 3 contents. Finally, we found that NOVELICA is tend to be less stressful and keeping arousal in learning mathematics.
\end{abstract}

Keywords: e-Learning, Remedial Education, Math Anxiety, Video Learning, Novel Game, Instructional Pacing

\section{Introduction}

There are many students who are not good at or have anxiety towards math [1]. Many situations exist in math above the high school level that require cross-referencing of knowledge of various units, and depending on the student, there are those who are good at and those who are not, creating the need for instructional pacing that suits the individual. In recent years there have been many examples of adaptive learning that introduce an e-Learning system as a follow-up to the one-to-many lecture format, and various systems are being developed according to use. In particular, the self-study system for visual lessons is easy to match to a schedule and is often used in universities and corporate training. However, some issues that are raised concerning these systems is that they don't take into account the pace of students, there's no interaction with a teacher, and it is difficult to maintain the motivation to study [2], which leads to stress during learning. It is known that stress during studying puts pressure on working memory and has a negative effect on learning study contents, and importance is being placed on stress management in school and at home [3][4]. Although stress comes from various sources, such as from a dislike of a subject or circumstances at home, either source negatively affects learning. There are numerous scales when speaking generally about instructional pacing, and we can even consider choosing what to study on a certain day based on a monthly study schedule as instructional pacing. Conventional systems split study into sections such as "trigonometric functions" and "differentials and integrals" according to a learner's comprehension and even use single lessons to keep up pace with the student. However, there has been no consideration made so far for attentive pacing corresponding to motivation and mood for studying in one lesson. To consider this, it will be necessary to review a new time structure that differs from that held by existing contents such as videos. Therefore, this study focuses on the time structuring of e-Learning 
systems and examines a statistical model of the time characteristics of comprehension of discussion contents within lessons by looking at how a majority of user utilize these systems. It also conducts a real-time appeal corresponding to the study situations of users and develops a system that assists in improving comprehension and maintaining concentration and study motivation. As a first step, this paper conducted a survey regarding how to split up time segments for study contents.

\section{Our Propose "NOVELICA"}

\subsection{Time structure of existing system}

The existing self-study e-Learning systems can be split up into the two types of automatic progression and manual progression when classifying it based on the pace of lesson progression, and each has their own issues.

The visual lesson system falls under automatic progression and basically progresses unilaterally without keeping pace with the student. Although it is possible to control it by changing playback speed, fast forwarding, or rewinding, it is difficult for listening again to speech when wanting to hear a part over again.

On the other hand, manual progression systems which primarily consist of text and illustrations are used quite often. This paper collectively refers to this type of system as the novel game format. Many of these systems which use study agents are also researched and are taken into consideration more so than visual lessons for their interactivity with students. But while they are tailored for carefully progressing through anxiety areas, there is the nuisance of the student being required to control progression all on their end. In addition, since contents with accompanying voices are often marked by separate speech units, the rhythms of pausing (intervals), speech speed, and pitch in voice conversations break down and don't allow for natural comprehension of voices (Fig. 1,2). The visual lesson system can be watched with comfort, and since the novel game system has the time structural advantage of being able to carefully read data, we examined a time segmenting method that allows us to incorporate both of these.

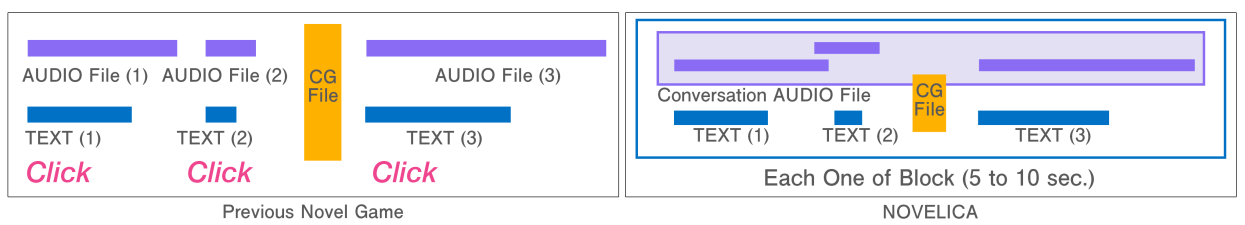

Fig. 1. Timing Structure of Novel Game

Fig. 2. Timing Structure of NOVELICA

\subsection{Summary of proposed system}

NOVELICA is a novel game system which splits lessons into time segments of single response prompts of conversations in order to solve the aforementioned issues. These are referred to as "blocks". One block consists of a single voice file, and text and images are displayed in sync with the conversation from that voice file. One block therefore maintains prosodic information intended by the teacher (Fig 1).

5 to 10 seconds is recommended for one block. Somewhere around this length is recommended since one response in a conversation can fit within this range. There is also no essential need for clicks in between each block, and a video experience is made possible by having the game automatically progress. A huge difference when compared with video is that the producer can insert click prompts (response prompts) in between blocks anywhere they choose. In other words, they can basically progress it automatically like a video while leaving it to the student to progress in situations where they want to put emphasis on speech or give the student time for deliberation. 
In addition, it is a semi-automatic type system that allows you to stop at the current block or jump to a block of your choice in the middle of automatic progression. Since speech can be cued for each block, listening back to topics can be carried out smoothly (Fig 3,4).

NOVELICA can be developed with normal novel-game engine. (ex. kirikiri, AIR Novel, Utage)

If you use our NOVELICA framework, you will be able to compose a lesson program easily. We estimate that it is easier than developing usual novel-game or video-lesson.

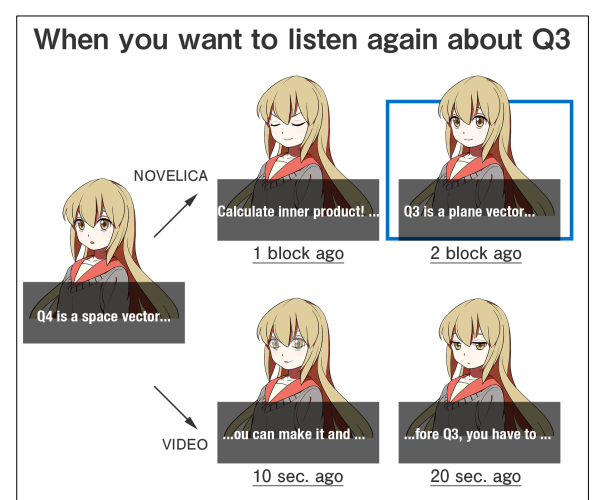

Fig. 3. System Reaction Difference Between NOVELICA and Videos

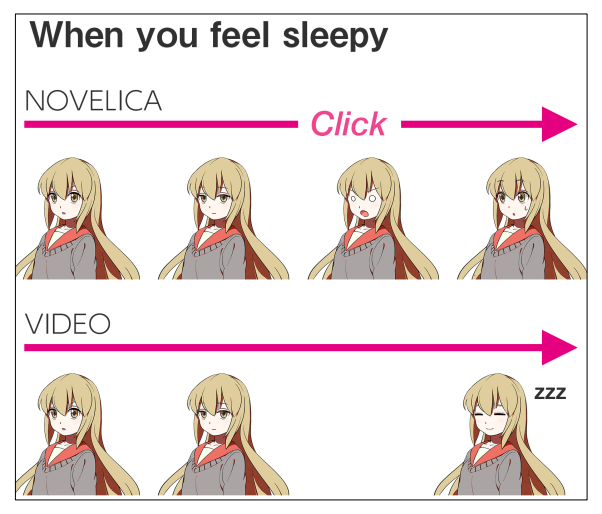

Fig. 4. Advantage of Semi-Automatic Progress

\section{Experiment}

\subsection{Summary of experiment}

This paper used the differentials and integrals volume of the math study assistance novel game " AKAHONe! Prototype A" in order to study how mood and psychological state changes when studying with NOVELICA compared to when studying with existing systems (Figure 5). This content was prepared as a novel game format with manual progression, the proposed method with semi-automatic progression, and a video format with automatic progression. The lesson contents including the characters and speech was exactly the same between these three conditions and only the progression type differed.

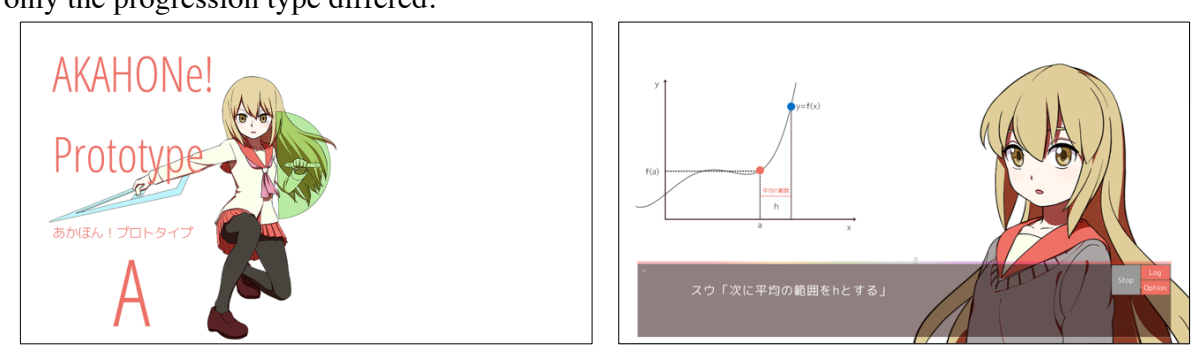

Fig. 5. AKAHONe! Prototype A

\subsubsection{Subjects}

21 men and women who had graduated high school and had at least somewhat weak at math cooperated as subjects for the experiment. They were chosen because high school graduates would have studied differentials and integrals in Math II B. Subjects were split into three groups 
consisting of (1) those receiving lessons using the novel game (manual progression type), (2) those receiving lessons using NOVELICA (semi-automatic progression type), and (3) those receiving lessons by watching videos (automatic progression type).

\subsubsection{Assessment method}

A Two-Dimensional Mood Scale (TDMS-ST) [5], POMS [6], and a verification test were applied for assessment.

The Two-Dimensional Mood Scale is a psychological scale that measures psychological state (mood) upon response to eight questions. POMS is a questionnaire method that assesses temporary moods and emotional states that change depending on the conditions the subject is put under. There are 65 questions which are condensed to 30 questions in the shortened version, and this method has a high degree of reliability. In accordance with the procedures of the short version of POMS [6], the stress score was taken to be the Total Mood Disturbance (TMD) score which is the total amount of the 5-scale score except with energetic being taken away.

\subsubsection{Experiment procedure}

After each participant answered the TMDS-ST a first time, they were asked to try out the contents and afterward respond a second time to the TMDS-ST as well as respond to the short version of POMS (Profile of Mood States) and a verification test. Through this the stress level during learning of all contents and change in mood was studied. In addition, after all items were responded to, they were asked to try out the remaining two contents and give their free opinion on how each compared to one another. Finally, subjects were asked to fill out a mathematical profile. The confirmation test consisted of questions like those in Table 1.

Table 1. Comprehension Check Test

\begin{tabular}{|c|l|}
\hline Q1 & $\begin{array}{l}\text { Explain the “Takashi underestimation } \\
\text { phenomenon (たかし過小評価現象)” } \\
\text { (You may use the figure) }\end{array}$ \\
\hline Q2 & $\begin{array}{l}\text { Which formula is the derivative of the } \\
\text { function } f(x) ? \\
1 . \quad f^{\prime}(a)=\lim _{h \rightarrow 0} \frac{f(a+h)-f(a)}{h} \\
\text { 2. } \quad f^{\prime}(x)=\lim _{h \rightarrow 0} \frac{f(x+h)-f(x)}{h}=\lim _{h \rightarrow 0} \frac{(x+h)^{2}-x^{2}}{h} \\
\text { 3. } \quad f^{\prime}(x)=\lim _{h \rightarrow 0} \frac{f(x+h)-f(x)}{h} \\
4 . \quad \int x^{n} d x=\frac{1}{n+1} x^{n+1}+C\end{array}$ \\
\hline Q3 & $\begin{array}{l}\text { Differentiate the constant C based } \\
\text { on the definition of derivative }\end{array}$ \\
\hline
\end{tabular}

Table 2. Mathematical Profile Sheet

\begin{tabular}{|c|}
\hline Questions about your math \\
\hline$\cdot$ Do you feel math anxiety? \\
\hline $\begin{array}{c}\text { Very High, High, M-H, Moderate, } \\
\text { M-L, Low, Nothing }\end{array}$ \\
\hline - What was the unit you were good at? \\
\hline$\cdot$ What was the unit you were weak at? \\
\hline $\begin{array}{l}\text { · If you have impressions or memories } \\
\text { about math, please describe. }\end{array}$ \\
\hline
\end{tabular}

\subsection{Results and consideration concerning stress}

The TMD score of POMS was taken as the stress score (average of 4.6). While the score and dispersion of Group 2 was the smallest, no significant difference was found. There were participants in groups 1 and 3 whose stress scores largely exceeded from the average of 10 points. Upon checking their profiles, it was found that group 1 was good at differentials while group 3 was weak at (the range of study including) differentials.

After performing a morpheme analysis of the free opinions and searching for frequent vocabulary, many people in group 1 explained that they were able to progress on their own but they found the clicking to be bothersome, while many in group 3 explained that they couldn't keep up with the tempo of the videos. Upon performing a chi-square test, a statistically significant correlation $(\mathrm{p}<.05)$ was verified wherein group 1 expressed their displeasure of the system citing that they had to make a lot of clicks, while group 3 also expressed displeasure towards the system 
citing that it was too fast to keep up with. From the above, it was confirmed that if someone was studying something they were good at, they were displeased with having to progress through the manual progression type system in detail by themselves, while if someone was studying something they were weak at, they were displeased with advancing through the automatic progression type system without being able to keep up with understanding it. Through this we can surmise that there are situations where someone can't create a good pace for themselves and feel strongly stressed. Meanwhile, the stress score for all participants in group 2 using NOVELICA was lower than 10.

With NOVELICA you can just watch or skip areas that you already know or don't need to listen to without having to control anything, and you can dedicate more time to areas you want to listen to again or concentrate on. Due to this, participants were able to create their own pace regardless of whether they were good or weak at differentials, which helped prevent stress.

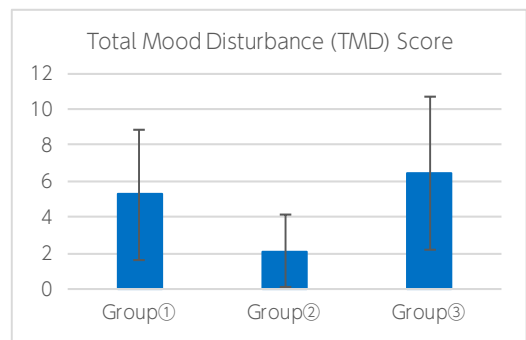

\begin{tabular}{|c|c|c|c|c|}
\hline & $\begin{array}{c}\text { TMD } \\
\text { Score }\end{array}$ & good at & weak at & Group \\
\hline $\begin{array}{c}\text { Partici } \\
\text {-pant1 }\end{array}$ & 20 & $\begin{array}{c}\text { Differential and } \\
\text { integral } \\
\text { Vector } \\
\text { Combinatorics }\end{array}$ & $\begin{array}{c}\text { Numerical } \\
\text { sequence } \\
\text { Limit }\end{array}$ & (1) \\
\hline P-3 & 21 & $\begin{array}{c}\text { Trigonometric } \\
\text { functions } \\
\text { Geometry }\end{array}$ & $\begin{array}{c}\text { Mathematics } \\
\text { II,B and later } \\
\text { general }\end{array}$ & (3) \\
\hline P-4 & 13 & $\begin{array}{c}\text { Differential } \\
\text { Geometry }\end{array}$ & $\begin{array}{c}\text { Integral } \\
\text { Probability } \\
\text { theory }\end{array}$ & (1) \\
\hline P-9 & 23 & Nothing & Overall & (3) \\
\hline
\end{tabular}

Fig. 6. Total Mood Disturbance Score Table 3. TMD Score and Mathematical Profile

\subsection{Results and consideration regarding content comprehension and arousal level}

The ratio of correct answers for the confirmation test was as follows for questions 1 to 3 . Question 1 was not too related to math and could be answered if someone understood the topic. Question 3 was an Advanced-level exercise and could not be answered except mainly by those who were good at differentials. Thus, the total score was only tallied for questions 1 and 2 . Group 2 had the highest ratio of correct answers, suggesting they were able to keep up with the lesson discussions. The difference between groups 1 and 2 is thought to be due to natural understanding of voices through maintaining prosodic information. Although the ratio of correct answers for group 3 for whom the rhythm of natural voices should have been natural, the free opinions revealed that some couldn't get into watching a video, found the experience passive, or felt they were being left behind, which means that one-sided viewing without interactivity makes it not possible to maintain concentration. The ratio of correct answers is thought to be low due to the number of things not heard increasing when unable to concentrate.
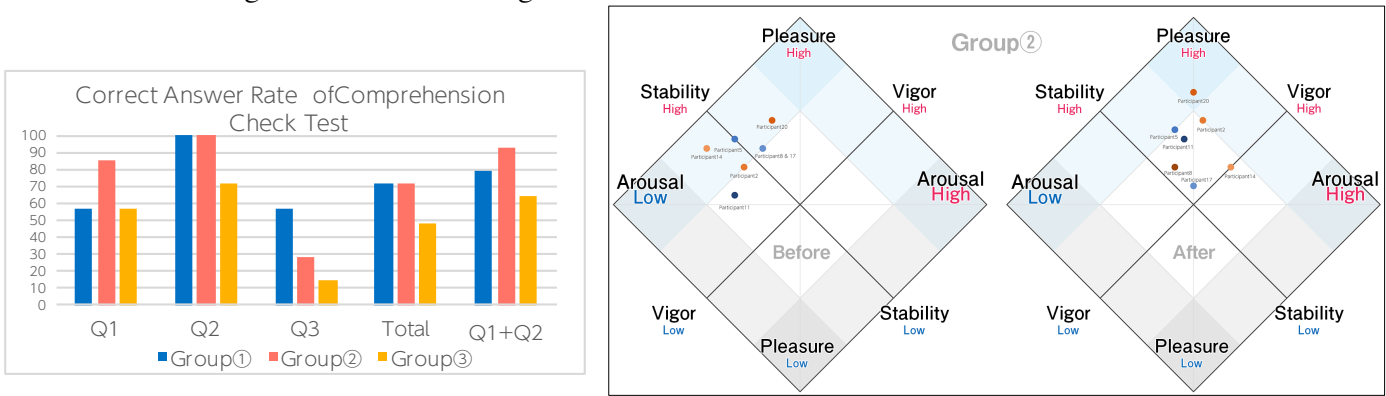

Fig. 7. Correct Answer Rate of Check Test

Fig. 8. TDMS-ST Result Group(2) 
We can estimate from the changes in arousal level whether the contents were faced head-on and an effort was made to study. Looking at the measurement results of the Two-Dimensional Mood Scale, we see that the arousal levels of all participants only rose for group 2. After studying with NOVELICA, six out of seven people changed to a normal mood state, and the remaining one person's mood changed to an area suitable for activity. NOVELICA has a time structure that differs from that of video or a novel game, and prompts can be inserted. This way it doesn't really feel like one-way viewing and a moderate arousal state can be maintained.

\section{Conclusion}

In this paper, we conducted a study concerning how to best split time segments for study contents that take into consideration attentive pacing corresponding to learning desire and mood during a lesson. The proposed system NOVELICA is a semi-automatic type novel game eLearning system that segments lessons into conversation block that are 5 to 10 seconds long so that one may interactively cue conversations while maintaining the prosodic information of voices.

21 men and women who had graduated high school and were weak at math were split into three groups and an experiment was conducted that had them study by means of (1) manual progression type contents, (2) semi-automatic progression contents, and (3) automatic progression contents. It was understood from an assessment of stress scores using the POMS that with NOVELICA, it is possible to create a suitable pace for oneself regardless of whether someone is good or weak at the study units, and it is possible to study in a low-stress state. In addition, results of the change measured in mood with a Two-Dimensional Mood Scale showed that inserting prompts with NOVELICA maintained a moderate state of arousal and comprehension of the lesson contents was promoted together with maintaining the prosodic information of voices.

These results indicated that NOVELICA's segmentation makes it possible to create individually suited lesson paces and acts as a time structure that reduces stress during learning and assists with comprehension. In the future, we expect that if we can appeal to real-time from the system side in accordance with the block transition state of the user, we can implement e-Learning with interactivity.

\section{References}

1. Gijsbert Stoet, Drew H. Bailey, Alex M. Moore, David C. Geary: Countries with Higher Levels of Gender Equality Show Larger National Sex Differences in Mathematics Anxiety and Relatively Lower Parental Mathematics Valuation for Girls, PLoS One. 2016; 11(4): e0153857.Published online 2016 Apr 21. doi: 10.1371/journal.pone.0153857 (2016)

2. R Nakamura, A Inoue, S Ichimura, K Okada, Y Matsushita: "Ghost-Tutor": A Learning Support System Suggesting Learning Pace for on-Demand Learning, IPSJ 47(7), pp.2099-2106 (2006)

3. Rose K. Vukovic, Michael J. Kieffer, Sean P. Bailey, Rachel R. Harari: Mathematics anxiety in young children: Concurrent and longitudinal associations with mathematical performance, Contemporary Educational Psychology Volume 38, Issue 1, January, pp.1-10 (2013)

4. Talia Berkowitz, Marjorie W. Schaeffer, Erin A. Maloney, Lori Peterson, Courtney Gregor, Susan C. Levine, Sian L. Beilock: Math at home adds up to achievement in school, Science. Vol. 350, October 9, p.196. (2015)

5. Y Sakairi, K Nakatsuka, T Shimizu: Development of the Two-Dimensional Mood Scale for selfmonitoring and self-regulation of momentary mood states, Japanese Psychological Research 55(4), (2013)

6. Kazuhito Yokoyama: POMS tanshukuban tebiki to jirei kaisetsu (in Japanese), KANEKOSHOBO (2005) ISBN 9784760840144 